\title{
A NEW TREND IN THE CREATION OF SMART MATERIALS: APPLICATION OF ELECTROCHEMICAL TECHNOLOGIES*
}

\author{
Sakhnenko M. D., Karakurkchi H. V.
}

\section{INTRODUCTION}

The modern trend of electrochemical materials science is the creation of smart materials with inexhaustible areas of application. But one of the most common problems hindering the introduction of such materials is their high cost, the need to attract precision equipment and high technology, multi-stage manufacturing processes. These and other factors, similar in nature, significantly constrain the use of such materials, and, on the other hand, contribute to the development of new technologies and the acquisition of new knowledge. One of the ways to overcome some of these problems is the use of smart materials not in the form of a consolidated substance, and coatings of varying thickness, formed on the surface of metal carriers. This allows to achieve significant savings of precious metals, alloys and their compounds. Such a methodology is almost always justified, because in the vast majority of cases the use of functional materials involves the work of only their surface layer. Therefore, protective, dielectric, catalytic, highconductivity, resistive and other properties are realized in thin surface layers, regardless of the degree of its roughness. To a large extent, this applies to the whole variety of metal oxide systems (MOS) - from monoxide composite (MOC) to heterooxide electrochemical coatings. However, views on the structure and phase formation in polymetallic and oxide systems differ, which does not allow from a single standpoint to carry out their design, and hence the optimization of production processes. Therefore, the development of a generalized description of the MOS is an urgent need today. So, we have proposed ${ }^{1}$ the latest method

* This research was conducted with the support of the Ministry of Education and Science of Ukraine within the confines of the project (Registration Number 0119U002568).

${ }^{1}$ Inversion of metal oxide composites structural matrixes Promising Materials and Processes in Applied Electrochemistry : monograph / N.D. Sakhnenko, M.V. Ved', A.V. Karakurkchi, M.V. Mayba ; editor-in-chief V.Z. Barsukov. Kyiv, 2018. P. 229-236. 
of constructing a phenomenological description of metal oxide systems, regardless of their nature and functional purpose.

\section{The current state of the problem and the working hypothesis}

At present, composite electrochemical coatings (CEPs) and materials with a metal matrix, in which oxides of aluminum, titanium, zirconium, or particles of other nature, such as carbides, borides, and others, are incorporated, play a significant role among galvanochemical coatings. The use of a metal matrix, which is formed on a metal substrate, has many advantages 2,3 .

At the same time, oxide and conversion coatings are no less common, mainly on valve metals - titanium, zirconium, aluminum, niobium, tantalum. In some industries (heterogeneous and photocatalysis, sensor elements, nano- and microelectronics) such oxide coatings include metals and their oxides as alloying components, which allows to significantly improve the functional properties of such heteroxide composites $^{4,5,6}$.

Among the practically implemented technologies of composite materials and coatings can be distinguished numerous groups of methods that differ in the principles of organization - metallurgical, thermal condensation, impregnation and firing, polymerization, sol-gel, etc. However, we can distinguish a set of electrochemical methods - cathodic deposition, anodic oxidation, including plasma electrolyte, electrophoresis. The hallmarks of these methods are single-stage, the possibility of implementation on serial equipment, a high level of

${ }^{2}$ Tseluikin V.N. On the Structure and Properties of Composite Electrochemical Coatings. A Review Protection of Metals and Physical Chemistry of Surfaces. 2016. Vol. 52. P. 254-266.

3 Modeling of the surface treatment of passive metals / M.V. Ved', M.D. Sakhnenko, O.V. Bohoyavlens'ka, T.O. Nenastina. Materials Science. 2008. Vol. 44. P. 79-86.

${ }^{4}$ Sakhnenko N.D., Ved M.V., Karakurkchi A.V. Nanoscale Oxide PEO Coatings Forming from Diphosphate Electrolytes. Nanophysics, Nanomaterials, Interface Studies, and Applications. Springer Proceedings in Physics, 2017. Vol. 195. P. 507-531.

${ }^{5}$ Mixed alumina and cobalt containing plasma electrolytic oxide coatings / G.Sh. Yar-Mukhamedova, M.V. Ved', A.V. Karakurkchi, N.D. Sakhnenko. IOP Conf. Series: Materials Science and Engineering. 2017. Vol. 213.

6 Cobalt and manganese oxide catalytic systems on valve metals in ecotechnologies Promising Materials and Processes in Applied Electrochemistry: monograph / A. Karakurkchi, M. Sakhnenko, M. Ved', A. Gorohivskiy, O. Galak, S. Menshov, O. Matykin ; editor-in-chief V.Z. Barsukov. Kyiv, 2017. P. 214-223. 
adaptation to automation and robotics, flexible process control, high productivity and other, no less important elements that make such technologies almost unalterable.

It can be argued that the range of electrochemical methods of surface treatment fully meets the requirements of modern technologies in the third industrial revolution and the transition to the fourth (Industry 4.0).

It should also be noted another, almost unrealized possibility of such technologies, in particular the ability to integrate in one technological cycle of several different galvanochemical methods of synthesis. As an example we can cite the technological chain implemented by us in the creation of magnetoelectric nanolaminates, which included plasma-electrolytic oxidation and electrophoretic deposition ${ }^{7}$. These theses are elements of a logical tuple that forms the basis for a new paradigm of electrochemical materials science in the field of creating smart materials is an inversion of the nature of the structural elements of metal oxide composites due to variation of technological principles and synthesis parameters .

Examples include systems such as $\mathrm{Ni}-\mathrm{TiO}_{2}, \mathrm{Ni}-\mathrm{Al}_{2} \mathrm{O}_{3}, \mathrm{Fe}-\mathrm{ZrO}{ }_{2}$ and others ${ }^{8,9}$, in which the structural elements "matrix" and "second phase" can be inverted by changing the modes and parameters of electrolysis and component composition of electrolytes. It is on such principles that it is possible to radically change the content and ratio of individual phases, to form a predetermined surface geometry - from almost mirror-shiny to evenly porous or with a high specific area. System research inversion of the structure of metal oxide composites will provide new knowledge about the factors influencing the fine structure of materials, detect quantum effects in nanoscale layers ${ }^{10,11}$, alloy such structures within a wide range of components, and conduct a targeted search for highly efficient materials and structures many branches of the industrial complex.

${ }^{7}$ Sakhnenko N.D., Ved' M.V., Mayba M.V. Konversionnye i kompozicionnye pokrytija na splavah titana: monografija. Kharkiv : NTU “KhPI” Publ., 2015. 176 p.

${ }^{8}$ Tushar Borkar, Sandip P. Harimkar. Effect of electrodeposition conditions and reinforcement content on microstructure and tribological properties of nickel composite coatings. Surface \& Coatings Technology. 2011. Vol. 205. P. 4124-4134.

9 Electrodeposition of composite $\mathrm{Fe}-\mathrm{TiO}_{2}$ coatings from methanesulfonate electrolyte / E.A. Vasil'eva, A.V. Tsurkan, V.S. Protsenko, F.I. Danilov. Protection of Metals and Physical Chemistry of Surfaces. 2016. Vol. 52. P. 532-537.

${ }^{10}$ Nanostructured Mixed Oxide Coatings on Silumin Incorporated by Cobalt / A.V. Karakurkchi, M.D. Sakhnenko, M.V. Ved', M.V. Mayba. Nanocomposites, Nanostructures, and Their Applications. Springer Proceedings in Physics, 2019. Vol. 221. P. 269-291.

11 Ternary cobalt-molybdenum-zirconium coatings for alternative energies / G. Yar-Mukhamedova, M. Ved', N. Sakhnenko, M. Koziar. Applied Surface Science. 2017. Vol. 421. P. 68-76. 
Note that a priori composite materials and coatings are synergistic structures in which the presence of several (at least two or more) components significantly increases the functional properties relative to the level of the original components.

\section{Formalized description of the inversion of two-component systems}

In our opinion, the generalized scheme of inversion of a twocomponent system formed by two metals and their compounds (M1 and M2) should be provided in the form of an oriented graph, which allows to visually display the nature of transformations and establish quantitative parameters of dynamics of these processes. We write down the transformations that will take place in such a metal oxide system in the form of gross equations, and we will associate the individual phases with the nodes of the graph.

These transformations include the formation of individual oxides

$$
\begin{gathered}
\mathrm{M} 1 \rightarrow(\mathrm{M} 1 \mathrm{Ox}), \\
\mathrm{M} 2 \rightarrow(\mathrm{M} 2 \mathrm{Oy}),
\end{gathered}
$$

and mixed oxide (heterometal oxide)

$$
(\mathrm{M} 1 \mathrm{M} 2) \rightarrow(\mathrm{M} 1 \mathrm{Ox} \cdot \mathrm{M} 2 \mathrm{Oy}) \text {. }
$$

In addition, take into account the formation of a bimetallic alloy (intermetallic), without taking into account the stoichiometric ratios of the components of the compound

$$
\mathrm{M} 1 \leftrightarrow(\mathrm{M} 1 \mathrm{M} 2) \leftrightarrow \mathrm{M} 2,
$$

as well as the actual composite with a metal matrix of varying nature

$$
\begin{aligned}
& \mathrm{M} 1 \rightarrow(\mathrm{M} 1 \cdot \mathrm{M} 2 \mathrm{Oy}) \leftarrow(\mathrm{M} 2 \mathrm{Oy}), \\
& \mathrm{M} 2 \rightarrow(\mathrm{M} 2 \cdot \mathrm{M} 1 \mathrm{Ox}) \leftarrow(\mathrm{M} 1 \mathrm{Ox}) .
\end{aligned}
$$

Naturally, equations (1) - (6) reflect only the meaning of the formation of phases, but not the mechanism of reactions, and in each case must be detailed. For example, the formation of $\mathrm{M} 1 \mathrm{Ox} \cdot \mathrm{M} 2 \mathrm{Oy}$ heteroxide can be provided as a consequence of the reactions along route (3), or as a result of partial transformations (1) and (2). In addition, such important conjugated and combined reactions should be considered. Such reactions can be: the release of hydrogen in the cathode reaction, and in the presence of solutions of electrolytes oxometallics (in particular, molybdenum and tungsten) and their stepwise reduction by electrochemical mechanism and the participation of hydrogen atoms ${ }^{12,13}$, as well as a number of others, no less significant transformations:

12 Refractory metals influence on the properties of $\mathrm{Fe}-\mathrm{Co}-\mathrm{Mo}(\mathrm{W})$ electrolytic alloys / M. Ved, I. Yermolenko, Yu. Sachanova, N. Sakhnenko. Materials Today: Proceeding. 2019. Vol. 6. P. 121-128. 


$$
\begin{gathered}
\mathrm{H}_{3} \mathrm{O}^{+}+\mathrm{e} \rightarrow \mathrm{H}_{\mathrm{ad}}+\mathrm{H}_{2} \mathrm{O}, \\
\mathrm{WO}_{4}^{2-}+4 \mathrm{H}^{+}+2 e \rightarrow \mathrm{WO}_{2}+2 \mathrm{H}_{2} \mathrm{O}, \\
\mathrm{WO}_{2}+4 \mathrm{H}_{\mathrm{ad}} \rightarrow \mathrm{W}+2 \mathrm{H}_{2} \mathrm{O} .
\end{gathered}
$$

Taking into account the above, the nodes of the state graph will be the following structural elements:

$$
\text { (M1), (M2), (M1M2), (M1Ox), (M2Oy), (M1Ox·M2Oy), }
$$
which include both individual metals (M1) and (M2) and their alloy (intermetallic) (M1M2), and monoxides (M1Ox) and (M2Oy), as well as heterooxide $(\mathrm{M} 1 \mathrm{Ox} \cdot \mathrm{M} 2 \mathrm{Oy})$.

Obviously, the set of the given equations and the corresponding links of the graph, reflecting the dynamics of transitions between its structural elements (10), allow to form a two-dimensional graphic image in the form of a cyclic figure. At the same time, to call it a graph is to some extent not quite correct, because in $2 \mathrm{D}$ format the graphic image will have intersecting edges, while according to the rules of graph construction such a procedure is unacceptable. However, this aspect of the proposed scheme reflects the main idea - the inversion of the structural matrices of CEP. But given the possibility of introducing another universal element of the graph - the intermediate Im, which corresponds to the set of intermediate states at all stages of transformation of the metal oxide system (alloying, forming a composite electrochemical or heteroxide coating, etc.), the generalized scheme takes a complete form.

The intensities of the transitions between the individual vertices of the graph in Fig.1. there are electrochemical reactions, the rates of which are determined by a significant number of factors (Fig. 2).

Among them are the nature, composition and ratio of electrolyte components, the nature of polarization (anode, cathode, reversible), electrolysis mode (stationary, non-stationary, pulsed, programmable, etc.), as well as its amplitude and time parameters ${ }^{14}$.

It is the combination of these and a significant number of other factors ultimately determine not only the composition of the consolidated material or coating, but also its structure and morphology, the degree of localization of individual phases, their distribution by material thickness, and finally properties and areas of application. It is clear that for the

${ }^{13}$ Composition, Morphology, and Topography of Galvanic Coatings $\mathrm{Fe}-\mathrm{Co}-\mathrm{W}$ and Fe-Co-Mo / I.Yu. Yermolenko, M.V. Ved', N.D. Sakhnenko, Yu.I. Sachanova. Nanoscale Research Letters. 2017. № 12:352.

14, Synthesis, and Diagnostics of Functional Galvanic Coatings Made of Multicomponent Alloys / M.D. Sakhnenko, M.V. Ved', I.Yu. Ermolenko, Yu.K. Hapon, Kozyar M.O. Design. Materials Science. 2017. Vol. 52. № 5. P. 680-686. 
formalization of polymetallic, in particular ternary systems, as noted in ${ }^{15}$, visualization in this way is difficult to do, here will be useful scientific work of physical chemistry on the topological description of multicomponent silicate systems.

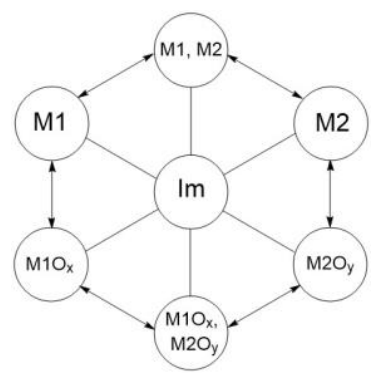

Fig. 1. Graph for states of bimetallic metal oxide system

The scheme shown in Fig. 1 has a deep philosophical connotation, as it represents some physico-chemical "avatar", as the embodiment of the relationship and interdependence of processes with their internal content and the beauty of external manifestation.

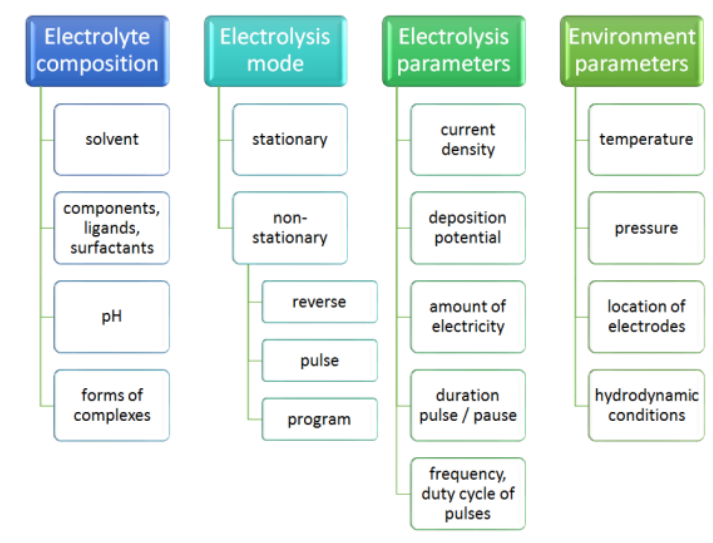

Fig. 2. External factors of electrolysis

15 Electrochemical Deposition of Fe-Mo-W Alloy Coatings from Citrate Electrolyte / A.V. Karakurkchi, M.V. Ved', I.Yu. Ermolenko, N.D. Sakhnenko. Surface Engineering and Applied Electrochemistry. 2016. Vol. 52. № 1. P. 43-49. 
An example of the implementation of mutual transformations in such a bimetallic system is the Ni-Al system (well known in metallurgy as PM-NYU50 according to TU 14-22-101-96). For such a system, the formation of the alloy can be realized by electrolysis in non-aqueous solutions, the formation of composites with metal and/or oxide matrices is widely known, and the heterooxide coating is applied in the mode of plasma-electrolytic oxidation. Thus, in particular, reinforcement of CEP with a nickel matrix of alumina increases the physical and mechanical properties of the composite ${ }^{16}$, and the incorporation of nanosized metal particles into the oxide matrix increases the chemical resistance of CEP in alkaline media and gives such a coating catalytic properties.

Another, very important aspect of the problem of inversion of matrices of metal oxide composites is the definition in their phase space of the area of implementation of a particular electrochemical technology.

If we denote the initial components of the metal oxide composite $\mathrm{A}$ and $\mathrm{B}$, and some functional property of the material as $\mathrm{X}$ (Fig. 3), the task will be to establish ways to control the synthesis of IOC in the range of changes in the composition of the composite $0 \leq \omega(\mathrm{A}) \leq \mathrm{A}_{\mathrm{m}}$ та $0 \leq \omega(B) \leq B m$. A characteristic feature of the dependence $X=f(A, B)$ will be, first, its extreme nature, which reflects the synergistic properties of the composite, and, secondly, the presence of a region of compositions $A m \leq \theta \leq B m$, for which the continuity of the functional is violated.

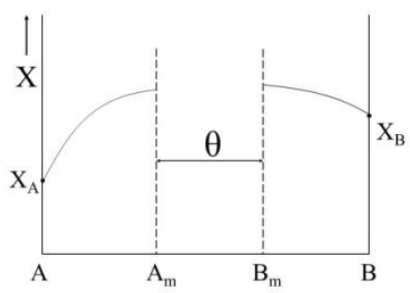

Fig. 3. Diagram for the state of a two-component system with a synergistic nature of the change in the property of $X$

The reason for this discontinuous nature of the dependence $\mathrm{X}=\mathrm{f}(\mathrm{A}, \mathrm{B})$ is the cancellation of the nature of electrochemical

${ }^{16}$ Sakhnenko M.D., Ved' M.V,. Ovcharenko O.O. Physicomechanical Properties of Composite Electrochemical Coatings and Foils Based on Nickel and Reinforced with $\mathrm{Al}_{2} \mathrm{O}_{3}$. Materials Science. 2017. Vol. 53. № 3. P. 374-384. 
processes that ensure the formation of the MOC of a certain composition in the intervals $0 \leq \omega(A) \leq A_{m}$ та $0 \leq \omega(B) \leq B_{m}$. If, for example, for MOS in the range $0 \leq \omega(\mathrm{M} 1) \leq \mathrm{Am}$ metal matrix of the composite is formed in the cathode reaction

$$
\mathrm{M}^{\mathrm{z}+}+\mathrm{ze} \rightarrow \mathrm{M}^{0}
$$

and the second phase is the oxide (M2Oy), which is obtained by reaction (2), the oxide matrix of the composite is the result of the anodic oxidation reaction of the component $\mathrm{B} 0 \leq \omega$ (M2Oy) $\leq \mathrm{Bm}$, and the strengthening phase - metal clusters A.

In such a system, the simultaneous course of conjugate reactions in the zone Am $\leq \theta \leq \mathrm{Bm}$ is not possible, because the driving force of the reactions are different in nature electrochemical reactions. The formalized state of such a metal oxide system is an open graph

$$
\mathrm{M}^{\mathrm{z}+} \rightarrow \mathrm{M}^{0} \rightarrow \theta \leftarrow(\mathrm{M} 2 \mathrm{Oy}) \leftarrow \mathrm{M} 2,
$$

in which in the area of compositions $\theta$ the driving force of transitions between separate states is not defined, in contrast to the simultaneous existence of structural elements of graph (12), from which the considered IOC is constructed.

But despite such a pessimistic scenario of analysis of the discontinuous graph of IOC states (12), there is a variant of approximation to the realization of the state $\theta \rightarrow 0$. That is, the annihilation of the uncertainty of the driving forces of transformations, namely the nature, intensity and parameters of electrochemical processes, which are the basis for the formation of the IOC precisely due to the inversion of their structural elements. If we consider the formation of IOC with oxometals, such as molybdenum or tungsten, we can see that the reduction of oxometalate ions to the metal occurs gradually through the formation of oxides in the intermediate oxidation state of $\mathrm{MO}_{\mathrm{x}}$ (where $\mathrm{M}=\mathrm{Mo}, \mathrm{W}, \mathrm{V} \ldots$...) The formed oxides subsequently participate in the subsequent electrochemical transformations with the formation of already phase metal precipitate. Note that a significant number of cathodic reactions is complicated by the presence of a partial reaction of hydrogen evolution (7), the ad atoms of which can participate in the subsequent reduction of intermediate oxides (9) with the formation of a metal coating. But it should be taken into account the fact that direct electrochemical formation of coatings with molybdenum, tungsten and a number of other metals from aqueous solutions is impossible, while with metals of the iron family, they co-precipitate in alloys. This is a prerequisite that the coating of the Mo composition $\left(\mathrm{MoO}_{\mathrm{x}}\right)$ under such conditions will no longer be monometallic. 
A detailed analysis of the influence of electrolysis conditions on the composition and morphology of coatings revealed the interesting fact that the composition of sediments, in particular the oxygen content, significantly depends on the nature of the polarization of the electrodes. Thus, with increasing current density of electrodeposition from $2 \mathrm{~A} / \mathrm{dm}^{2}$ to $4 \mathrm{~A} / \mathrm{dm}^{2}$ in coatings formed by direct current, there is an increase in the amount of oxygen from 36 to 47 at.\% (Fig. 4), which is due to insufficiently complete processes of reduction of intermediate oxides of molybdenum to metallic molybdenum.

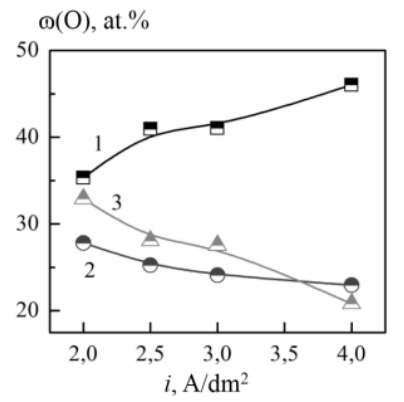

Fig. 4. Influence of current density on the oxygen content in the composition of Fe-Co-Mo coatings depending on the electrolysis mode:

1 - galvanostatic, 2 - pulse, $t_{\text {on }} / t_{\text {off }}=5 \mathrm{~ms} / 10 \mathrm{~ms} ; 3-$ pulse, $t_{\text {on }} / t_{\text {off }}=10 \mathrm{~ms} / 50 \mathrm{~ms}$

For coatings obtained by pulsed electrolysis at a ratio of pulse time to pause time $t_{\mathrm{on}} / t_{\mathrm{off}}=5 \mathrm{~ms} / 10 \mathrm{~ms}$, the dependences differ with increasing cathode current density. It was found (Fig. 4) that the oxygen content decreases to 24 at. $\%$, and with increasing the duration of the pause to $50 \mathrm{~ms}$ - up to 21 at. $\%$.

Another confirmation of the above thesis on the influence of hydrogen atoms on the course of the cathode process is the dependence of the alloy current on the alloy current density of the polarization (Fig. 5).

It is interesting to note that the electrolytic hydrogen, which is released in the combined reaction (7), which is usually considered to be excessive electricity consumption for a non-target process, in this case is an example of a positive effect on the result of electrolysis. Indeed, the performance of the electrolytic hydrogen generation process depends only on the polarization current density. Therefore, the amount of electricity expended on this reaction does not depend on the nature of the polarization - galvanostatic or pulsed. At the same time, the current yield 
of the alloy in the pulsed mode is $10-15 \%$ higher than that of galvanostatic due to the positive role of hydrogen atoms, which due to participation in reaction (9) increase the yield of the target product - the metal component of the composite.

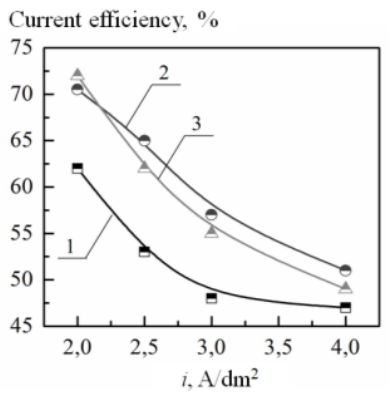

Fig. 5. Influence of current density on the current output of Fe-Co-Mo alloys obtained in the following modes: 1 - galvanostatic, 2 - pulse, $t_{\text {on }} / t_{\text {off }}=5 \mathrm{~ms} / 10 \mathrm{~ms}$; 3 - pulse, $t_{\text {on }} / t_{\text {off }}=10 \mathrm{~ms} / 50 \mathrm{~ms}$

Taking into account the obtained results, it can be concluded that electrodeposition of coatings with Fe-Co-Mo alloy can be performed both in the galvanostatic mode and by polarization with a unipolar pulsed current. Coatings obtained by direct current, due to a much higher amount of oxygen are classified as composite materials, and the use of pulsed electrolysis is appropriate for the formation of more uniform metal coatings, in which the amount of incorporated oxide phase is less. It is from such structural elements that the coating of the composition $\mathrm{M}\left(\mathrm{MO}_{\mathrm{x}}\right)$ is formed, which contains both metal and metal oxide components. It should be noted that by definition it is a monometallic system in which both the oxide phase and the metal matrix are formed by the same element. In this case, a number of properties of such MOS fully correspond to the definition of synergistic compositions $X=f(M, M O x)$ in particular by microhardness, photo- and electrocatalytic properties, etc. ${ }^{17}$. Note that to consider such an IOC as a model version of the inversion of the structural elements of the IOC is quite difficult.

${ }^{17}$ Influence of the contents of refractory components on the corrosion resistance of ternary alloys based on iron and cobalt / Yu.I. Sachanova, I.Yu. Ermolenko, M.V. Ved', M.D. Sakhnenko, T.O. Nenastina, G.Sh. Yar-Mukhamedova. Materials Science. 2019. Vol. 54. № 4. P. 556-566. 


\section{CONCLUSIONS}

Based on the results of the analysis of information sources, a phenomenological description of metal oxide systems with a wide range of applications, the synthesis technologies of which have an electrochemical basis. It is proposed to construct the description of the state of such systems with the involvement of graph theory, which provides an opportunity to visually reflect the nature of transformations and to establish quantitative parameters of the dynamics of these processes as the intensity of transitions between individual states. A generalized inversion scheme of a two-component bimetallic system is constructed, which takes into account the presence of individual metals, their alloy (intermetallic), two monoxides and a heteroxide compound. The factors influencing the nature and intensity of transitions between graph nodes are analyzed and an example of inversion of structural elements of metal oxide composite is given. The influence of electrolysis regimes on the formation of the oxygen-containing component of the composite was analyzed on the example of Fe-Co-Mo alloy coatings and the role of hydrogen atoms in the formation of composites with the participation of oxometallate ions was highlighted.

\section{SUMMARY}

The paper presents the results of research on the creation of so-called smart materials using electrochemical technologies. It is shown that the basis for the creation of smart materials is the inversion of the nature of the structural elements of metal oxide composites due to the variation of technological principles and synthesis parameters.

A generalized inversion scheme of a two-component bimetallic system has been developed, which takes into account the presence of individual metals, their alloy (intermetallic), two monoxides and a heteroxide compound.

The factors influencing the nature and intensity of transitions between graph nodes are analyzed and an example of inversion of structural elements of metal oxide composite based on the analysis of electrosynthesis of Fe-Co-Mo coatings is given.

\section{References}

1. Inversion of metal oxide composites structural matrixes Promising Materials and Processes in Applied Electrochemistry: monograph / N.D. Sakhnenko, M.V. Ved', A.V. Karakurkchi, M.V. Mayba ; editor-inchief V.Z. Barsukov. Kyiv, 2018. P. 229-236. 
2. Tseluikin V.N. On the Structure and Properties of Composite Electrochemical Coatings. A Review Protection of Metals and Physical Chemistry of Surfaces. 2016. Vol. 52. P. 254-266.

3. Modeling of the surface treatment of passive metals / M.V. Ved', M.D. Sakhnenko, O.V. Bohoyavlens'ka, T.O. Nenastina. Materials Science. 2008. Vol. 44. P. 79-86.

4. Sakhnenko N.D., Ved M.V., Karakurkchi A.V. Nanoscale Oxide PEO Coatings Forming from Diphosphate Electrolytes. Nanophysics, Nanomaterials, Interface Studies, and Applications. Springer Proceedings in Physics, 2017. Vol 195. P. 507-531.

5. Mixed alumina and cobalt containing plasma electrolytic oxide coatings / G.Sh. Yar-Mukhamedova, M.V. Ved', A.V. Karakurkchi, N.D. Sakhnenko. IOP Conf. Series: Materials Science and Engineering. 2017. Vol. 213.

6. Cobalt and manganese oxide catalytic systems on valve metals in ecotechnologies Promising Materials and Processes in Applied Electrochemistry : monograph / A. Karakurkchi, M. Sakhnenko, M. Ved', A. Gorohivskiy, O. galak, s. Menshov, O. matykin ; editor-inchief V.Z. Barsukov. Kyiv, 2017. P. 214-223.

7. Sakhnenko N.D., Ved' M.V., Mayba M.V. Konversionnye i kompozicionnye pokrytija na splavah titana : monografija. Kharkiv : NTU “KhPI” Publ., 2015. 176 p.

8. Tushar Borkar, Sandip P. Harimkar. Effect of electrodeposition conditions and reinforcement content on microstructure and tribological properties of nickel composite coatings. Surface \& Coatings Technology. 2011. Vol. 205. P. 4124-4134.

9. Electrodeposition of composite $\mathrm{Fe}-\mathrm{TiO}_{2}$ coatings from methanesulfonate electrolyte / E.A. Vasil'eva, A.V. Tsurkan, V.S. Protsenko, F.I. Danilov. Protection of Metals and Physical Chemistry of Surfaces. 2016. Vol. 52. P. 532-537.

10. Nanostructured Mixed Oxide Coatings on Silumin Incorporated by Cobalt / A.V. Karakurkchi, M.D. Sakhnenko, M.V. Ved', M.V. Mayba. Nanocomposites, Nanostructures, and Their Applications. Springer Proceedings in Physics, 2019. Vol. 221. P. 269-291.

11.Ternary cobalt-molybdenum-zirconium coatings for alternative energies / G. Yar-Mukhamedova, M. Ved', N. Sakhnenko, M. Koziar. Applied Surface Science. 2017. Vol. 421. P. 68-76.

12.Refractory metals influence on the properties of $\mathrm{Fe}-\mathrm{Co}-\mathrm{Mo}(\mathrm{W})$ electrolytic alloys / M. Ved, I. Yermolenko, Yu. Sachanova, N. Sakhnenko. Materials Today: Proceeding. 2019. Vol. 6. P. 121-128. 
13. Composition, Morphology, and Topography of Galvanic Coatings Fe-Co-W and Fe-Co-Mo / I.Yu. Yermolenko, M.V. Ved', N.D. Sakhnenko, Yu.I. Sachanova. Nanoscale Research Letters. 2017. № $12: 352$.

14.Design, Synthesis, and Diagnostics of Functional Galvanic Coatings Made of Multicomponent Alloys / M.D. Sakhnenko, M.V. Ved', I.Yu. Ermolenko, Yu.K. Hapon, M.O. Kozyar. Materials Science. 2017. Vol. 52. № 5. P. 680-686.

15. Electrochemical Deposition of Fe-Mo-W Alloy Coatings from Citrate Electrolyte / A.V. Karakurkchi, M.V. Ved', I.Yu. Ermolenko, N.D. Sakhnenko. Surface Engineering and Applied Electrochemistry. 2016. Vol. 52. № 1. P. 43-49.

16. Sakhnenko M.D., Ved' M.V,. Ovcharenko O.O. Physicomechanical Properties of Composite Electrochemical Coatings and Foils Based on Nickel and Reinforced with $\mathrm{Al}_{2} \mathrm{O}_{3}$. Materials Science. 2017. Vol. 53. № 3. P. 374-384.

17. Influence of the contents of refractory components on the corrosion resistance of ternary alloys based on iron and cobalt / Yu.I. Sachanova, I.Yu. Ermolenko, M.V. Ved', M.D. Sakhnenko, T.O. Nenastina, G.Sh. Yar-Mukhamedova. Materials Science. 2019. Vol. 54. № 4. P. 556-566.

\section{Information about the authors:} Sakhnenko Mykola Dmytrovych, Doctor of Technical Sciences, Professor, Head of the Department of Physical Chemistry National Technical University "Kharkiv Polytechnic Institute" 2, Kyrpychova str., Kharkiv, 61002, Ukraine

Karakurkchi Hanna Volodymyrivna, Doctor of Technical Sciences, Senior Researcher, Senior Researcher at the Department of Physical Chemistry National Technical University "Kharkiv Polytechnic Institute" 2, Kyrpychova str., Kharkiv, 61002, Ukraine 